\title{
O QUE AS ORGANIZAÇÕES ENTENDEM POR GESTÃO DE TALENTOS?
}

\author{
Dayane Scopel Ferrazza* \\ daya.ferrazza@gmail.com \\ Cecília Gerhardt Burtet* \\ cecilia.burtet@gmail.com \\ Angela Beatriz Busato Scheffer* \\ angela.scheffer@ufrgs.br \\ *Universidade Federal do Rio Grande do Sul - Porto Alegre, RS
}

http://dx.doi.org/10.1590/1413-2311.0162014.49054

Recebido em 06/05/2014

Aprovado em 07/10/2015

Disponibilizado em 01/04/2015

Avaliado pelo sistema double blind review

Revista Eletrônica de Administração

Editor: Luís Felipe Nascimento

ISSN 1413-2311 (versão on line)

Editada pela Escola de Administração da Universidade Federal do Rio Grande do Sul.

Periodicidade: Quadrimestral

Sistema requerido: Adobe Acrobat Reader.

\section{RESUMO}

Este estudo objetiva discorrer sobre práticas que constituem a denominada Gestão de Talentos (GT) no universo corporativo. O tema que, segundo o estudo da SHRM (2013), ocupa, desde 2010, a primeira posição na lista de prioridades dos líderes de RH, aparece também no Brasil como tendência principal em políticas e práticas de Gestão de Pessoas (GP). A denominada guerra pelos talentos associa-se a um momento de transição da sociedade industrial para a pós-industrial. Apesar de ser um tema emergente e presente em muitos debates mundiais que abordam o futuro da GP, observa-se ainda confusão nas definições existentes sobre os termos talento e Gestão de Talentos, instigando o questionamento: o que especificamente é Gestão de Talentos? Embora reconheçam a carência de uma definição consistente sobre o termo, alguns autores afirmam que uma boa GT é muito importante para a estratégia da empresa. A Gestão de Talentos não tem ainda um significado claro. A multiplicidade de conceitos revela a necessidade de estudos que ofereçam avanços significativos no entendimento do assunto. Em que realmente acreditam as empresas que hoje utilizam a expressão Gestão de Talentos em seus discursos e práticas de gestão? Em que a GT se diferencia da GP? Qual o objetivo da identificação e/ou diferenciação dos talentos dentro de cada estrutura organizacional pesquisada? A presente pesquisa propõe, através de análise comparativa, uma reflexão sobre tais inquietações. Para isso foram entrevistados gestores de três organizações de natureza distinta, todas de grande porte, localizadas no estado do Rio Grande do Sul, região sul do Brasil, tendo elas um elemento em comum: a presença do termo Gestão de Talentos em suas retóricas. A análise comparativa dos resultados oferece avanços na compreensão do assunto e demonstra a confusão de conceitos ainda existente, possível reflexo da atual miscelânea literária de definições. 
Palavras-Chave: Gestão de Talentos; Talentos; Gestão de Pessoas.

\title{
WHAT DO ORGANIZATIONS UNDERSTAND ABOUT TALENT MANAGEMENT?
}

\begin{abstract}
This study aims to discuss practices that constitute the so-called Talent Management (TM) in the corporate universe. The subject, according to the SHRM study (2013), has ranked first in the priority list of HR leaders since 2010, also appears in Brazil as a major trend in policies and practices Personnel Management (PM). The so-called war for talent is associated with a time of transition from an industrial society to post-industrial one. Despite being an emerging issue present in many global debates that address the future of PM, it is still observed that there is some confusion in the existing definitions on talent and Talent Management terms, prompting the question: What is Talent Management specifically? While acknowledging the lack of a consistent definition of the term, some authors state that a good TM is of utmost importance to the company's strategy. It is a known fact that Talent Management does not have, in fact, a clear meaning. The multiplicity of concepts indicates the need for studies that provide significant advances in the understanding of the subject. In what do these companies which currently use the expression Talent Management in its speeches and management practices truly believe? How does TM differs from PM? What is the purpose of identification and/or differentiation of talent within each organizational structure searched? This Research proposes, through a comparative analysis, a reflection on these concerns. To do so, three managers from three different and distinct nature organizations were interviewed. These three companies were all large companies, located in the state of Rio Grande do Sul, southern area of Brazil and have an element in common: the term Talent Management in their rethoric. The comparative analysis of the results offers advances in the understanding of the subject and demonstrates a confusion of concepts that still exists, the possible effect of the current literary miscellany of definitions.
\end{abstract}

Keywords: Talent Management; Talents; People Management.

¿QUÉ ENTIENDEN LAS ORGANIZACIONES ACERCA DE LA GESTIÓN DE TALENTO?

\section{RESUMEN}

Este estudio tiene como objetivo discutir las prácticas que constituyen la denominada Gestión de Talento (GT) en el universo corporativo. El tema, según el estudio de SHRM (2013), ocupa el primer lugar en la lista de prioridades de los líderes de RRHH desde 2010, también aparece en Brasil como tendencia importante en las políticas y prácticas de Gestión de Personal (GP). La llamada guerra por talentos se asocia con un tiempo de transición de una sociedad industrial a post-industrial. A pesar de ser un tema emergente presente en muchos debates globales que abordan el futuro del GP, todavía se observa cierta confusión en las definiciones existentes en términos de talento y Gestión de Talento, lo que llevó a la pregunta: ¿Qué es la Gestión de Talento en concreto? Aunque reconozcan la falta de una definición coherente del término, algunos autores afirman que una buena GT es de suma importancia para la estrategia de la empresa. Eso porque la Gestión del Talento no tiene un significado claro. La multiplicidad de conceptos indica la necesidad de estudios que ofrezcan avances significativos en la comprensión de la materia. ¿En que creen las empresas que hoy en día

REAd | Porto Alegre - Edição 80 - N 1 - janeiro/abril 2015 - p. 222-247 
O que as organizações entendem por gestão de talentos?

utilizan la expresión de Gestión de Talento en sus discursos y prácticas de gestión? ¿Cómo se difiere la GT de la GP? ¿Cuál es el propósito de la identificación y/o diferenciación de talento dentro de cada estructura organizacional investigada? Esta investigación propone, a través de un análisis comparativo, una reflexión sobre estas preocupaciones. Para ello, se entrevistaron directivos de tres organizaciones de distintas naturalezas situadas en el estado de Rio Grande do Sul, en la región sur de Brasil. Todas las tres son de grande porte y poseen un elemento común: la presencia del término "Gestión de Talento" en su retórica. El análisis comparativo de los resultados ofrece avances en la comprensión de la materia y demuestra una confusión de conceptos que todavía existe y el posible efecto de la miscelánea literaria actual de las definiciones.

Palabras Clave: Gestión de Talento; Talentos; Gestión de Personal.

\section{INTRODUÇÃO}

A migração da economia manufatureira para a economia de serviços integra as transformações no sistema produtivo e no mercado de trabalho, acarretando a mudança de perfil dos trabalhadores, o que, consequentemente, demanda uma nova atuação da área de Gestão de Pessoas (LEGGE, 2005). A denominada guerra pelos talentos associa-se a um momento específico de transição da sociedade industrial para a pós-industrial. Os impactos no mercado de trabalho, no perfil de profissionais e nas relações de trabalho causados por essa transformação levaram as organizações a reavaliarem suas práticas de Gestão de Pessoas, como forma de obter vantagem competitiva (ALMEIDA, 2004).

Na literatura nacional e internacional, o tema Gestão de Talentos (GT) está entre as principais tendências na área de Gestão de Pessoas (GP) (SARSUR et al., 2003; BARRETO et al., 2010; FREITAG et al., 2011, 2012; SHRM, 2013). Em âmbito internacional, a Society of Human Resource Management (SHRM) publicou um relatório bianual - resultado de pesquisa realizada com profissionais da área de $\mathrm{RH}$ - trazendo as principais tendências que devem impactar o mercado de trabalho nos próximos anos. O relatório de 2013 revela que a Gestão de Talentos ocupa a primeira posição na lista de prioridades dos líderes de RH desde o ano de 2010, indicando que, em todos os países do mundo, os profissionais dessa área seguirão elegendo a GT como seu foco primordial (SHRM, 2013). No Brasil, Barreto et al. (2010), ao identificarem os principais desafios e tendências em Gestão de Pessoas para o ano de 2015, concluíram que a Gestão de Talentos ocupa o topo da lista de tendências em políticas e práticas de GP no país.

Apesar de ser um tema emergente e presente em muitos debates mundiais que abordam o futuro da Gestão de Pessoas, observa-se uma verdadeira confusão nas definições REAd | Porto Alegre - Edição 80 - N 1 - janeiro/abril 2015 - p. 222-247 
Dayane Scopel Ferrazza, Cecília Gerhardt Burtet \& Angela Beatriz Busato Scheffer

existentes sobre os termos talento e Gestão de Talentos, instigando o questionamento: o que especificamente é Gestão de Talentos? (LEWIS; HECKMAN, 2006). Embora reconheçam a carência de uma definição única, clara e consistente sobre o termo, Ashton e Morton (2005) afirmam que uma boa GT é de extrema importância para a estratégia da empresa. A Gestão de Talentos não tem, de fato, um significado claro, é latente, pois, a necessidade de estudos empíricos que identifiquem tal expressão e promovam discussões sobre o assunto no país (FREITAG et al., 2012).

A multiplicidade de conceitos marca a ausência de clareza e evidencia a necessidade de avanços significativos no entendimento do assunto. Diante disso, questiona-se: em que realmente acreditam as empresas que hoje utilizam a expressão Gestão de Talentos em seus discursos e práticas de gestão? Em que a Gestão de Talentos se diferencia da Gestão de Pessoas? Qual o objetivo da identificação e/ou diferenciação dos talentos dentro de cada estrutura organizacional pesquisada?

O presente estudo pretende responder essas questões a partir da visão de gestores atuantes em organizações de naturezas distintas, porém com um elemento em comum: a presença do termo Gestão de Talentos em suas retóricas. O objetivo central é traçar uma análise comparativa entre três organizações de grande porte, localizadas no município de Porto Alegre/RS, buscando conhecer as práticas que constituem aquilo que cada uma denomina Gestão de Talentos.

Para a análise conceitual dos usos do conceito 'Gestão de Talentos', além de se verificar, na prática, como ele é entendido e usado, também é discutida brevemente a abordagem de Ryle (1953) sobre o uso ordinário/cotidiano dos termos, tal como presente em alguns artigos (Oliveira-Castro, 1993; Oliveira-Castro; Oliveira-Castro, 2001). Ryle (1953) explica que a linguagem cotidiana dos termos descreve uma 'vida mental', uma crença, uma ideia que nem sempre correspondem a uma prática. Oliveira-Castro e Oliveira-Castro (2001) referem que, quando um conceito é 'importado' da linguagem cotidiana para a linguagem científica, ele traz consigo uma carga de conotações, muitas das quais passam despercebidas no uso supostamente técnico.

Revela-se ainda notória confusão de conceitos sobre o tema. Tal situação possibilitaria estabelecer uma inconsistência entre teoria e prática, não fosse a ampla variedade de entendimentos encontrada na própria literatura. Nessa abordagem, não se propõem técnicas ou métodos de identificação, retenção ou desenvolvimento de talentos, procura-se aqui o entendimento de sua gestão no universo organizacional. 
O que as organizações entendem por gestão de talentos?

\section{FUNDAMENTAÇÃO TEÓRICA}

A abordagem do tema Gestão de Talentos inicia-se invariavelmente pela discussão sobre a definição do termo talento, seguida da reflexão acerca do que seria a Gestão de Talentos. Optou-se, portanto, por apresentar a fundamentação teórica em dois subcapítulos. O primeiro expõe as variadas definições de 'talento' e o segundo exibe a tentativa de definir Gestão de Talentos, tendo como base a literatura nacional e internacional.

\subsection{Talento: ensaio de definição}

Embora pareça lógico iniciar com a abordagem do conceito de talento, uma vez que demarca o público-alvo da denominada Gestão de Talentos, as definições muitas vezes carecem de clareza. As organizações frequentemente buscam, na literatura, uma melhor compreensão do conceito de talento, porém as discussões existentes pouco auxiliam o entendimento e até mesmo o dificultam.

Gois et al. (2014) expõem uma série de noções de uso comum na literatura sobre talento: aparecem desde citações bíblicas até conceitos adotados em diferentes áreas científicas. Oliveira-Castro e Oliveira-Castro (2001) e Oliveira-Castro (1993), com base em Ryle (1953), demonstram como um conceito, quando 'importado' da linguagem cotidiana para qualquer linguagem científica, carrega consigo diferentes conotações, muitas das quais passam despercebidas no uso supostamente técnico.

No campo das organizações, a chamada guerra pelos talentos foi oficialmente lançada, no ano de 1998, pela McKinsey \& Company, empresa americana de consultoria, através da publicação de uma pesquisa realizada com mais de 90 empresas e cerca de seis mil gerentes e executivos. Tal estudo concluiu que, nas próximas décadas, os talentos constituirão o recurso corporativo mais importante e valioso. Para McKinsey, talento é um termo que identifica os 'melhores e mais brilhantes' (BEECHLER; WOODWARD, 2009), remetendo à noção comum de ser diferente, sendo uma característica de alguns indivíduos apenas. A expressão também foi cunhada por Michaels et al. (2001), os quais consideram talento as habilidades de um indivíduo, incluindo a habilidade de aprender e crescer. Lembrando a análise realizada por Oliveira-Castro e Oliveira-Castro (2001), observa-se a relação com o uso cotidiano do conceito, neste caso de talento, ligando-o a habilidades específicas. 
Muitas empresas buscam uma definição convincente de talento, a fim de identificá-lo e valorizá-lo em suas equipes, porém outras tantas organizações utilizam a palavra talento como sinônimo de toda a sua força de trabalho, contrariando a noção anterior pela qual nem todos podem ser designados talentos. Predomina, neste caso, uma noção mais ligada às possibilidades. Apesar destas percepções concorrentes de talento, a abordagem de 'estrela' ainda é a mais utilizada e difundida no universo corporativo (BEECHLER; WOODWARD, 2009). Sarsur et al. (2003) observam que, na literatura nacional e internacional, o uso do termo talento é frequentemente associado à figura de pessoas extraordinárias, propagando a ideia de que tais indivíduos constituem uma minoria, uma elite, e como tal devem ser tratados. Alinhada a esta ideia, Almeida (2004, p. 16) sustenta que "o termo talento refere-se, com frequência, à pessoa que traz em sua bagagem um conjunto privilegiado de competências, isto é, conhecimentos, habilidades e atitudes que a diferencia de outras", deste modo nem todos podem ser considerados talentos.

Para Ross (2013), a definição de talento também encontra suas origens na noção de diferenciação, de acordo com a maior capacidade de sucesso em comparação com outras pessoas Muitas organizações elegem este caminho para a identificação de seus talentos. $\mathrm{O}$ resultado? Uma busca desenfreada por características específicas que indicam maior capacidade e que diferenciam os talentos daqueles que, presumivelmente, não o são, gerando uma relação causal entre talento e sucesso, como se o sucesso fosse garantia certa para os talentosos e vice-versa.

Em geral, as concepções de talento complementam-se na noção de que pessoas talentosas são aquelas que põem em prática suas capacidades, visando atingir melhores resultados para a organização. Esta, por sua vez, tem como dever motivar e permitir a manifestação interna de seus talentos (ALMEIDA, 2004). Tal percepção aproxima-se muito da literatura existente sobre Gestão por Competências. Percebe-se aqui a relação com uma noção de ação, uma ação desempenhada com sucesso, algo que se manifesta na prática de um sujeito. Ao associar-se a sucesso, cabe refletir sobre que noção de sucesso é essa, de que contexto cultural advém (Oliveira-Castro; Oliveira-Castro, 2001).

Ross (2013) acredita que uma abordagem baseada em competências para identificação de talentos simplesmente substitui o desafio de definir 'talento' pelo desafio de identificar as competências desejadas para determinados papéis, em um ambiente que muda constantemente. A autora defende que o mesmo acontece quando talento é definido como potencial, visto que, se as organizações lutam para definir talento, vão lutar ainda mais para determinar se o indivíduo tem ou não potencial.

REAd | Porto Alegre - Edição 80 - N 1 - janeiro/abril 2015 - p. 222-247 
O que as organizações entendem por gestão de talentos?

\subsection{Gestão de talentos: uma variedade de conceitos}

Identificar o significado preciso de Gestão de Talentos é uma tarefa difícil, uma vez que os termos 'gestão de talentos', 'estratégia de talento', 'gestão de sucessão' e 'planejamento de Recursos Humanos' são frequentemente utilizados como sinônimos, evidenciando assim uma verdadeira confusão entre as muitas definições, termos e suposições feitas por autores que abordam a questão (LEWIS; HECKMAN, 2006).

Lewis e Heckman (2006), ao fazerem uma revisão da literatura internacional produzida sobre o tema, identificaram três perspectivas acerca da GT. A primeira perspectiva, vista por eles como supérflua por não oferecer avanço na compreensão do assunto, define a GT como o conjunto de práticas típicas da área de RH executadas de forma mais ágil. Tal concepção exige que a área faça o que sempre fez, porém com mais rapidez, o que para Collings e Mellahi (2009) significa simplesmente substituir o rótulo de Gestão de Talentos para Gestão de Recursos Humanos. A segunda vertente sugere que a GT esteja atrelada ao planejamento sucessório e/ou de Recursos Humanos dentro da organização, concentra-se principalmente no conceito de talent pools e repete muito do trabalho feito nos dois processos citados, não apresentando, dessa forma, qualquer avanço teórico ou prático. A terceira perspectiva, e talvez a mais problemática na concepção dos autores, foca a gestão de pessoas talentosas de forma mais genérica, ou seja, profissionais altamente competentes devem ser atraídos e devidamente retidos, independente de suas funções específicas. Essa abordagem sugere que as empresas devem, em geral, gerenciar a performance de seus talentos de forma indiferenciada, cabendo ao RH gerir todos os de alto desempenho. A iniciativa de gerir o talento inerente a cada pessoa pode ser bem intencionada, mas não é estratégica, uma vez que não oferece nenhuma orientação para o direcionamento e a alocação de recursos.

Às três vertentes descritas por Lewis e Heckman (2006), Collings e Mellahi (2009) adicionam uma quarta corrente de pensamento, na qual sugerem a identificação de posiçõeschave que afetam de forma diferenciada a vantagem competitiva da empresa. Entendido dessa forma, o ponto de partida da GT passa a ser o reconhecimento de posições altamente relevantes, seguido do desenvolvimento de um pool de talentos, os quais devem assumir papéis relacionados distintamente com a estratégia da empresa, sendo necessária a diferenciação entre os profissionais que são talentos estratégicos e aqueles que não o são.

REAd | Porto Alegre - Edição 80 - Nº 1 - janeiro/abril 2015 - p. 222-247 
A GT tão discutida atualmente e adotada por algumas organizações é, para Almeida (2004), uma atuação integrada da área de Recursos Humanos focada em estratégias organizacionais e competências. A autora fortalece a primeira perspectiva de Lewis e Heckman (2006), ao sustentar que a GT é um enfoque estratégico dos processos de captação, seleção, retenção e desenvolvimento do talento individual e organizacional. Consoante com a terceira vertente, Michaels et al. (2001) acreditam que as empresas devem procurar preencher suas posições, independente de quais forem, com profissionais altamente competentes e a GT deve ser feita através da classificação dos funcionários de acordo com seu desempenho. $\mathrm{O}$ objetivo da GT passa a ser identificar os talentos (profissionais com melhor desempenho, de acordo com os autores), bem como os demais funcionários que apresentam desempenho mediano ou insatisfatório, para então definir o desenvolvimento das pessoas dentro da organização. A ideia é orientar a força de trabalho em sua totalidade para o alcance de alta performance, trabalhando para que o desempenho mediano possa atingir a excelência em todas as funções e eliminando qualquer desempenho insatisfatório.

Ashton e Morton (2005) defendem a ideia de que GT pode ser uma abordagem estratégica e holística para o planejamento do RH e do negócio ou uma nova rota para eficácia organizacional. Embora reconheçam a carência de uma definição única, clara e consistente sobre o termo, afirmam que uma boa GT é de grande extrema importância para a estratégia da empresa.

Ao analisarem a produção brasileira e estrangeira sobre Gestão de Talentos no campo da Gestão de Pessoas, Freitag et al. (2012) constataram atributos relativos à performance, potencial e à competência nas definições e abordagens encontradas. Eles concluíram que, no Brasil, essas características emergiram de uma literatura contemporânea que versa sobre potencial e competência aliada à entrega.

Segundo Dutra (2004), é possível reconhecer a existência de duas grandes correntes que lançaram estudos de apoio ao debate e ao desenvolvimento do conceito de competência. A corrente norte-americana apoia-se em autores como Boyatz e McClelland, os quais entendem a competência como um estoque de qualificações (conhecimentos, habilidades e atitudes) que credencia a pessoa a exercer determinado trabalho. A corrente francesa, representada principalmente por autores franceses (Le Boterf, 1999, e Zarifian, 1999, por exemplo), associa a competência não a um conjunto de qualificações do indivíduo, mas às realizações da pessoa em determinado contexto, ou seja, àquilo que ela provê, produz ou entrega no trabalho. Conforme esses autores, o fato de o indivíduo deter as qualificações necessárias para uma atividade não assegura que ele entregará o que lhe é demandado. Dessa REAd | Porto Alegre - Edição 80 - N 1 - janeiro/abril 2015 - p. 222-247 
O que as organizações entendem por gestão de talentos?

forma, o conceito de competência não estaria associado à ideia de agregação de valor e entrega a determinado contexto independente do cargo, isto é, a partir da própria pessoa.

A competência, para McClelland (1973), é uma característica subjacente a uma pessoa. Tal característica pode ser relacionada com o desempenho superior na realização de uma tarefa ou em determinada situação. Este conceito designa um talento natural da pessoa, o qual pode ser aprimorado com habilidades, as quais seriam a demonstração, na prática, de um talento particular e de conhecimentos (aquilo que a pessoa precisa saber para desempenhar uma tarefa).

Zarifian (2001) desloca o foco que estava sobre o estoque de conhecimentos e habilidades para a forma como a pessoa mobiliza esse estoque e seu repertório em determinado contexto, de modo a agregar valor ao meio no qual está inserida.

O referencial apresentado evidencia a atualidade do tema. A multiplicidade de conceitos indica a carência de clareza, relacionada também à linguagem cotidiana e às diferentes conotações que daí derivam, como anteriormente discutido, e a necessidade de avanço no entendimento do assunto. Neste contexto, indaga-se: em que, de fato, acreditam as empresas que hoje utilizam a expressão Gestão de Talentos em seus discursos e práticas de gestão? Em que a Gestão de Talentos se diferencia da Gestão de Pessoas? Qual o objetivo da identificação e/ou da diferenciação dos talentos dentro de cada estrutura organizacional pesquisada? O presente estudo pretende responder essas questões, a partir da visão de gestores atuantes em organizações de naturezas distintas, porém com um elemento em comum: a presença do termo Gestão de Talentos em suas retóricas. Entende-se que a prática recorre ao conceito que o indivíduo tem do fenômeno. Os procedimentos metodológicos realizados estão detalhados a seguir.

\section{METODOLOGIA}

O estudo caracteriza-se como pesquisa exploratória, pois tem por objetivo principal de entender os processos e conceitos envolvidos na denominada Gestão de Talentos, em três organizações de grande porte, situadas na capital do estado do Rio Grande do Sul, Porto Alegre. A metodologia de pesquisa exploratória visa "proporcionar maior familiaridade com o problema, com vistas a torná-lo mais explícito” (GIL, 2009, p.41). Inserido neste contexto, encontra-se a pesquisa qualitativa, que responde a questões muito particulares, preocupandose com um nível de realidade que não pode ser quantificado. A finalidade real da pesquisa REAd | Porto Alegre - Edição 80 - N 1 - janeiro/abril 2015 - p. 222-247 
Dayane Scopel Ferrazza, Cecília Gerhardt Burtet \& Angela Beatriz Busato Scheffer

qualitativa não é contar opiniões ou pessoas, mas explorar o espectro de opiniões e as diferentes representações sobre o assunto em questão (BAUER; GASKELL, 2012).

A pesquisa qualitativa não procura enumerar ou medir os eventos estudados, nem emprega instrumental estatístico na análise dos dados. Ela parte de questões ou focos de interesses amplos, que vão se definindo à medida que o estudo se desenvolve. Os pesquisadores qualitativos estão preocupados com o processo e não simplesmente com os resultados ou produto. $\mathrm{O}$ interesse está em verificar como determinado fenômeno se manifesta nas atividades, nos procedimentos e nas interações diárias (GODOY, 1995).

A escolha das organizações que serviram como objetos de pesquisa prendeu-se à sua natureza, ao ramo de atuação e à utilização do termo Gestão de Talentos em seus discursos e/ou práticas de gestão. Assim foram selecionadas: uma empresa do setor de comunicação (Empresa A); uma multinacional do setor de tecnologia e desenvolvimento de software (Empresa B); uma instituição pública (Instituição). Por se tratar de um estudo de caso com base em organizações de grande porte, não se pretende, com o presente artigo, esgotar as análises e as reflexões acerca das discussões sobre a definição de Gestão de Talentos nos contextos pesquisados.

Os dados para a pesquisa foram coletados através de abordagem qualitativa, por meio de entrevistas semiestruturadas com alguns gestores representantes de cada organização. $\mathrm{O}$ método de coleta de dados escolhido permitiu que fossem "feitas perguntas controladas pela teoria e direcionadas para as hipóteses" (FLICK, 2009), de forma não só a direcionarem para as respostas das indagações a serem esclarecidas no presente artigo, mas também a abrirem possibilidades de serem exploradas pelos entrevistadores, a fim de buscar questões mais complexas e desbravar aspectos mais profundos acerca do tema abordado. Para a análise dos dados, utilizou-se o método de análise de conteúdo, o qual, segundo Bardin (2009), constituise em um conjunto de técnicas de análise das comunicações que permite ultrapassar as incertezas e enriquecer a leitura dos dados coletados.

Os dados foram coletados durante os meses de junho e julho de 2013. Ao todo foram ouvidos 12 profissionais das organizações selecionadas: um gestor de Recursos Humanos de cada uma delas e outros funcionários de áreas variadas, tais como comercial, tecnologia, produção e fiscal. Considerou-se o grande valor que gestores de outras áreas, externas ao RH, poderiam adicionar à análise aqui proposta, visto serem eles os responsáveis pela GT no dia a dia de suas equipes. Isto justifica a decisão de ponderar não apenas o entendimento da área de Recursos Humanos, mas também buscar conhecer a percepção de outros gestores que mostram um olhar desprendido do discurso e mais voltado à prática. $\mathrm{O}$ grupo participante da REAd | Porto Alegre - Edição 80 - Nº 1 - janeiro/abril 2015 - p. 222-247 
O que as organizações entendem por gestão de talentos?

pesquisa caracterizou-se por ser predominantemente masculino, com participação de apenas três pessoas do sexo feminino. Todos tinham formação superior, tendo a maioria completado pós-graduação (especialização, MBA, mestrado ou doutorado) em áreas diversas. A média de idade dos participantes era de 36 anos, com sujeitos na faixa entre 27 e 51 anos. Nas Empresas A e B, os entrevistados possuíam, em média, três anos e meio de casa e, na Instituição, 19 anos.

As entrevistas foram iniciadas com a pergunta filtro: 'A organização trabalha com o conceito de Gestão de Talentos?'. A partir da resposta afirmativa a esse questionamento efetuaram-se outras perguntas que levavam ao entendimento mais aprofundado da dinâmica da Gestão de Talentos dentro das unidades estudadas, bem como à concepção de talento que cada uma sustenta. As entrevistas foram gravadas e transcritas para análise, mediante consentimento dos entrevistados.

As organizações pesquisadas mostraram, em sua totalidade, grande entusiasmo em participar da pesquisa e contribuíram significativamente através de respostas detalhadas e profundas, sem incorrer em diálogos superficiais, assim tornando mais rica a análise. A fim de garantir o sigilo e resguardar a ética da pesquisa, identificam-se as empresas de comunicação e tecnologia com as letras A e B, respectivamente, e a organização pública pesquisada como Instituição.

\section{ANÁLISE DE RESULTADOS}

Para análise dos dados coletados, as informações foram categorizadas de acordo com as questões levantadas na pesquisa. Primeiro aborda-se, conforme a visão e o entendimento dos respondentes, o conceito de talento em relação ao que é praticado nas organizações em que atuam. Posteriormente, analisa-se em que, na percepção dos entrevistados, a Gestão de Talentos se diferencia da Gestão de Pessoas. Por fim, verifica-se a opinião dos sujeitos participantes em relação aos objetivos que levaram as respectivas organizações, em suas práticas de gestão, a optarem pela identificação e/ou diferenciação de talentos.

Antes de desenvolver as categorias definidas, ressalta-se que as organizações, objetos do presente estudo, se encontravam, no momento da coleta de dados, em steps diferentes no que se refere à Gestão de Talentos. Isto enriqueceu a pesquisa, por possibilitar a análise desse suposto novo modelo de gestão em diferentes fases de maturação. Na Empresa A, o programa de Gestão de Talentos estava em fase de implantação. A primeira avaliação para identificação 
Dayane Scopel Ferrazza, Cecília Gerhardt Burtet \& Angela Beatriz Busato Scheffer

dos talentos estava agendada para setembro de 2013. Na Instituição, a GT encontrava-se em fase embrionária e de planejamento na área de RH, mas, mesmo assim, buscou-se ouvir a opinião e conhecer o entendimento dos demais gestores até aquele momento. Na Empresa B, o discurso é de que a empresa já nasceu com esse estilo de gestão, considerado pelos respondentes um traço marcante na identidade dessa organização.

Constam, no Quadro 1, os principais achados da pesquisa, distribuídos pelas categorias definidas sob o olhar de cada organização estudada.

Quadro 1 - Quadro Comparativo Categorias versus Organizações

\begin{tabular}{|c|c|c|c|}
\hline Categoria / Organização & Empresa A & Empresa B & Instituição \\
\hline $\begin{array}{l}\text { Fase de maturação / step de } \\
\text { implantação }\end{array}$ & $\begin{array}{l}\text { Processo de GT em fase de } \\
\text { implantação com critérios bem } \\
\text { definidos pelo RH, porém esses } \\
\text { parâmetros ainda não se } \\
\text { encontram difundidos para } \\
\text { todos os gestores da } \\
\text { organização. } \\
\end{array}$ & $\begin{array}{l}\text { A GT é vista como parte } \\
\text { integrante da gestão, sem } \\
\text { relação com uma estratégia } \\
\text { específica, traduz-se como um } \\
\text { traço marcante na identidade } \\
\text { dessa empresa. }\end{array}$ & $\begin{array}{l}\text { GT encontra-se em fase } \\
\text { embrionária e de planejamento na } \\
\text { área de RH. }\end{array}$ \\
\hline Quem é talento? & $\begin{array}{l}\text { Colaboradores com desempenho } \\
\text { diferenciado e alta capacidade } \\
\text { de aprendizado. }\end{array}$ & \begin{tabular}{|l|} 
Conceito de talento atrelado ao \\
alinhamento do perfil \\
profissional à cultura da empresa \\
e ao alto rigor no processo \\
seletivo, que permite enquadrar \\
como talento todos que \\
ingressam na organização.
\end{tabular} & $\begin{array}{l}\text { Falta clareza no coneito. Em alguns } \\
\text { momentos, todos os profissionais } \\
\text { são considerados talentos, pois } \\
\text { detêm amplo conhecimento } \\
\text { técnico, advindo de exigências do } \\
\text { concurso público extremamente } \\
\text { disputado em âmbito nacional. Em } \\
\text { outros momentos, talentos são os } \\
\text { servidores que entregam algo a } \\
\text { mais. }\end{array}$ \\
\hline \multicolumn{4}{|c|}{ A Gestão de Talentos está inserida na Gestão de Pessoas, sendo uma parte dela. } \\
\hline $\begin{array}{l}\text { No que a Gestão de Talentos } \\
\text { se diferencia da Gestão de } \\
\text { Pessoas? }\end{array}$ & \begin{tabular}{|l|} 
GT consiste em ações de \\
desenvolvimento individuais \\
que abrangem um público menor \\
da organização (os intitulados \\
talentos), enquanto a GP \\
consiste em ações corporativas \\
direcionada a todos os públicos. \\
\end{tabular} & \begin{tabular}{|l|} 
Presença de duas opiniões \\
contrárias. Dos três \\
entrevistados, um reconhece a \\
diferença existente em função da \\
necessidade de direcionar \\
investimentos. Os demais \\
afirmam que ambos os conceitos \\
em nada diferem, sendo Gestão \\
de Talentos um nome moderno \\
para GP.
\end{tabular} & $\begin{array}{l}\text { GP resume-se ao cumprimento das } \\
\text { obrigações legais, enquanto à GT } \\
\text { cabe gerir aspectos } \\
\text { comportamentais do indivíduo - } \\
\text { assemelhando-se muito à } \\
\text { abordagem de Gestão por } \\
\text { Competências. }\end{array}$ \\
\hline $\begin{array}{l}\text { Que motivos levaram à } \\
\text { adoção desse estilo de } \\
\text { gestão? }\end{array}$ & $\begin{array}{l}\text { Excelência operacional, } \\
\text { vantagem competitiva, } \\
\text { direcionamento de recursos e } \\
\text { obtenção de profissionais } \\
\text { capacitados a assumirem } \\
\text { posições-chave. }\end{array}$ & $\begin{array}{l}\text { O ramo de atuação (tecnologia) e } \\
\text { a natureza do negócio exigem } \\
\text { uma força de trabalho composta, } \\
\text { em sua totalidade, por talentos. }\end{array}$ & $\begin{array}{l}\text { Necessidade de qualificação do } \\
\text { corpo gerencial para melhor } \\
\text { atender as exigências da sociedade } \\
\text { e de ajustes na atual GP para que } \\
\text { proporcione o devido acolhimento } \\
\text { da Geração Y. }\end{array}$ \\
\hline
\end{tabular}

Fonte: elaborado pelos autores 
O que as organizações entendem por gestão de talentos?

\subsection{Quem é talento afinal?}

Um aspecto importante, na presente categoria, é o fato das características principais atribuídas aos intitulados talentos aparecerem, em sua maioria, vinculadas ao alto desempenho, quer ele seja relacionado exclusivamente a uma capacidade técnica ou também esteja atrelado a aspectos comportamentais.

Considerando a visão da gestora de RH da Empresa A, tem-se uma definição de talento voltada para a vertente do alto desempenho dos colaboradores, somado ao alto nível de capacidade de aprendizado. Esta percepção assemelha-se, em parte, à abordagem de Michaels et al. (2001) que consideram talento as habilidades de um indivíduo, incluindo a habilidade de aprender e crescer. Para esta gestora, talentos são os profissionais que apresentam desempenho diferenciado "e associado a esse desempenho é o quanto essa pessoa tem condições de aprender em curto espaço de tempo e conseguir de fato ter maior contribuição pra empresa". O domínio do conceito apresentado pela área de RH é claro e demonstra o embasamento em critérios a serem levados em consideração na hora de mensurar a capacidade de aprendizado. Trazendo à tona a visão dos gestores das outras áreas, percebe-se um alinhamento conceitual em relação à importância do desempenho e da capacidade de aprendizado do colaborador para definir se ele deve ou não ser considerado um talento. Ainda faltam, porém, critérios padronizados que definam o que é talento dentro da organização, independente do que o gestor considera relevante para sua área de atuação. Essa carência ocorre fundamentalmente em função dos conceitos de talento e de Gestão de Talentos ainda se encontrarem em fase de especificação pela equipe de Recursos Humanos.

Ainda a respeito da Empresa $\mathrm{A}$, embora a implantação de critérios únicos, à época da entrevista, ainda estivesse no plano das ideias do RH, todos os gestores entrevistados explicitaram, naturalmente, a definição do que é um talento de acordo com a visão que cada um tem e o estilo de gestão que exerce. Embora com linguagens diferentes, todos apresentaram o conceito de talento atrelado, primeiro, ao alto desempenho e, segundo, à alta capacidade de aprendizado. O Gestor de Marketing diz que um talento "tem um ciclo de aprendizado rápido" e "tem um potencial de desenvolvimento também rápido, ou seja, em um curto espaço de tempo eles vão se transformar ou em um especialista muito forte ou em um gestor importante". Apesar da percepção, entre os gestores, de um conceito uniforme, ficou evidente que o processo de identificação de talentos ainda é desconhecido por eles, pois transpareceram sentir falta de critérios claros para a definição, pelo RH, do que é talento. $\mathrm{Ou}$ 
seja, a identificação do talento fica a cargo do gestor e de sua percepção sobre as características importantes para a identificação de um colaborador como talento ou não. Isto torna a definição mais informal, subjetiva e individualizada.

Então os meus critérios para definir o que é talento são diferentes dos de outro
gestor, e quando a gente vai multiplicando isso na empresa fica difícil depois fazer
uma comparação porque talvez ambos estejam certos, só que a empresa não tem
grana pra investir em 800 mil pessoas. Então quem a gente escolhe como talento?
(Diretor Comercial Empresa A)

Diferente da Empresa A, a Empresa B e a Instituição identificam, no primeiro momento, todos os seus colaboradores como talentos, embora por razões diversas. Durante o discurso, revelam características mais distintivas desse público, no qual alguns parecem ser 'mais talentos' que outros. Na Empresa B, atuante do setor de tecnologia e desenvolvimento de software, há divergência na visão dos três gestores entrevistados no que diz respeito à elucidação do termo talento. Um deles diz que talento é o profissional que se mostra alinhado aos valores organizacionais. Neste caso, vale informar que a organização trabalha sustentada sobre três pilares, os quais constituem seus princípios e diretrizes, que ultrapassam as capacidades técnicas. A lógica em seu discurso mostra que apenas candidatos alinhados aos três pilares são admitidos na organização. Isto indica que todos os profissionais que ingressam na empresa são vistos por ela como talentos. Essa visão é condizente com a gestão genérica de talentos, apresentada por Lewis e Heckman (2006) na terceira perspectiva traçada e criticada por ambos. Na avaliação deste autores, a iniciativa de gerir o talento inerente a cada pessoa pode ser bem intencionada, mas não é nem um pouco estratégica, uma vez que não oferece qualquer orientação para o direcionamento e a alocação de recursos. Parte da justificativa dessa definição de talento está vinculada ao ramo de atuação da Empresa B que, devido à comercialização de serviços customizados, consegue operar com um quadro funcional devidamente ajustado e dele exige uma capacidade técnica elevada para garantir a qualidade do trabalho entregue.

Saindo de uma visão mais generalizada, que vincula talento aos valores e à cultura organizacional, mas permanecendo na análise da Empresa B, observa-se que o líder da área responsável por alguns programas de Gestão de Pessoas e o Gerente Geral da região Nordeste expressam um conceito que se assemelha, em parte, ao conceito defendido pela área de $\mathrm{RH}$ da Empresa A: "Eu acho que o conceito ainda tá bastante atrelado a potencial. Potencial e performance das pessoas". Essa definição de talento ligado ao potencial, quer para desempenhar algum papel diferente em um projeto, quer pela capacidade de atuar como líder, 
O que as organizações entendem por gestão de talentos?

revela um olhar mais individual da organização sobre seus talentos, na identificação de suas capacidades e habilidades. A formulação deste conceito aproxima-se da abordagem de Michaels et al. (2001) sobre talento. Percebe-se haver uniformidade no conceito expresso por esses dois gestores, pois ambos sustentam que a organização é constituída somente por talentos, ou seja, todos os profissionais são mapeados como potenciais e têm capacidade de atingir elevado nível de desempenho.

A Instituição, terceira organização pesquisada, pertence ao setor público. Grande parte dos depoimentos de seus entrevistados revela como primeira percepção a de que todos os seus servidores são talentos. A gestora de Recursos Humanos percebe que "na realidade a gente começa com a régua bem em cima, porque a gente começa com um concurso público que seleciona o conhecimento técnico dos melhores". Almeida (2004), ao falar de captação e seleção de talentos na administração pública, destaca que as estatísticas de concursos exibem candidatos com qualificações muito altas concorrendo a cargos com níveis de exigência menores. Com frequência, pessoas com formação superior e pós-graduadas candidatam-se para cargos de nível médio. Devido ao processo seletivo, se estabelece, portanto, uma relação direta do termo talento com a habilidade técnica que o indivíduo detém. Na tentativa de atribuir características específicas a um público que fará parte de uma gestão diferenciada cujos integrantes serão, por consequência, denominados talentos, a Instituição busca diferenciá-los. Ela caracteriza os talentos como os profissionais "que além de fazer tudo isso, de cumprirem as metas, terem seus resultados, se dispõe a mais. Então participam de comissões, participam de auditorias extraordinárias, tem um foco, são especialistas em algum conhecimento." (Coordenadora de RH da Instituição). O Diretor Geral acredita que "de uma forma mais popular, talento seria essa facilidade que algumas pessoas podem ter em comparação a outras para o desempenho de algumas atividades diferentes, ou com mais potencialidade.".

A intenção de criar mecanismos e critérios comportamentais para a distinção entre o que é talento e o que não é sustenta-se, principalmente, em uma teoria que se assemelha muito ao conceito das características dos profissionais contemplado pela Gestão por Competências.

Eu diria que essas pessoas são talentos, que detém conhecimentos, formações diferenciadas, atitudes, sobretudo que adotem posturas, tomem atitudes diferentes, que se engajem de forma diferente. Eu diria que talentos seriam aquelas pessoas que seriam valorizadas dentro da organização e é valorizado aquele que faz isso, aquele que entrega um pouco mais. (Diretor da Escola Superior de Gestão da Instituição) 
Tal qual o uso de termos como inteligência/inteligente, discutido em Oliveira-Castro e Oliveira-Castro (2001), com base em Ryle (1953), verifica-se que, nas empresas, o uso de talentos está relacionado a uma condição de sucesso, também exercendo função adverbial. Ou seja, relacionam-se mais a ações desempenhadas com sucesso e que representam exercício de algumas habilidades, remetendo à noção de saber como realizar algo muito bem. A função adverbial não indica ações específicas, mas, muito mais, formas de realizar quase qualquer ação.

Como prática, o estudo mostrou que as visões e as formas de identificação do que é talento são diferentes tanto em uma organização e em outra como entre gestores da mesma organização, evidenciando a carência do conceito no que diz respeito a critérios claros e concisos para a caracterização do indivíduo como um talento ou não. Essa lacuna abre margem para que os gestores apropriem-se do conceito existente por trás da Gestão por Competências, a fim de definir talento ou, até mesmo, evidenciar a importância de aspectos exclusivos de determinada função e/ou projeto ou para relacioná-lo a usos cotidianos do termo.

Quando, entretanto, as empresas questionam o que torna alguém mais talentoso que outro ou procuram definir o que seja talento, percebe-se uma tentativa de organizar, de alguma maneira, a capacidade de entrega de seus colaboradores, quer para dimensionar investimentos em desenvolvimento, quer para observar, mais de perto, a evolução de suas carreiras, enquanto os denominados 'menos talentosos' ficam à margem de uma gestão corporativa, comum a todos os demais.

\subsection{Gestão de talentos: modernização ou subconjunto da gestão de pessoas?}

Ao serem questionados sobre em que a Gestão de Talentos difere da Gestão de Pessoas, a maioria dos entrevistados considerou que a Gestão de Talentos consiste em uma 'espécie do gênero Gestão de Pessoas'. Na Empresa A, a GT se diferencia da GP principalmente "no tempo e no sacrifício", segundo o Diretor Comercial. A Gestão de Pessoas ocorre no dia a dia, através de programas formatados para atender as necessidades e demandas gerais da organização. A Gestão de Talentos é orientada, na visão dos gestores de outras áreas, para dar maior atenção àqueles sujeitos 'talentosos' e ao investimento prioritário em ações de desenvolvimento a eles direcionadas, em detrimento de ações voltadas aos demais. 
O que as organizações entendem por gestão de talentos?

Então é importante alimentar essa pessoa com projetos diferentes que vão além daquele que ela recém entregou. Assim, eu acho que a gente não tem como fazer isso pra todas as pessoas de um time, mas pra talentos, que são os $5 \%$ ou $10 \%$ do time de um gestor, esses tem que trazer mais junto, tem que dar mais exposição, dar projetos diferenciados pra ele desenvolver. (Gerente Executivo de Tecnologia da Empresa A)

A natureza de negócio da Empresa A aparece como característica importante na distinção entre Gestão de Pessoas e Gestão de Talentos. Tanto o Gerente de Marketing quanto a Gestora de RH da organização expressam a percepção de que é inviável, para uma empresa de grande porte que quer se manter no mercado, possuir um quadro funcional composto unicamente por talentos, pois a Gestão de Talentos exige uma remuneração acima da média e a oferta constante de oportunidades desafiadoras para esses profissionais, ou seja, "a gente tem níveis de investimento diferentes, a gente tem preocupações diferentes, são dois universos completamente distintos." (Gerente de Marketing Empresa A). Em uma diferenciação mais conceitual dos programas de GP e GT, a Gestora de RH dessa empresa afirma que a Gestão de Talentos está fundamentada nos conceitos-base da Gestão de Pessoas, porém “na Gestão de Talentos eu tenho modelos específicos que estão relacionados muito mais ao desenvolvimento individual do que ao corporativo". Fica claro, portanto, que a Gestão de Talentos é pensada apenas para os profissionais caracterizados como tal, os quais, nessa empresa, constituem minoria. Isto reforça a abordagem de Sarsur et al. (2003), os quais observam que o uso do termo talento é frequentemente associado a pessoas extraordinárias, uma elite, que como tal deve ser tratada. Nesse aspecto, diferente de outros, a perspectiva da Empresa A se afasta da abordagem de Michaels et al. (2001), segundo a qual todos os cargos devem ser preenchidos extraordinariamente com alto desempenho, ignorando tanto a possibilidade de o desempenho competente poder ser perfeitamente aceitável em algumas posições, como a possibilidade de a empresa poder optar por maximizar as capacidades organizacionais em determinadas competências em detrimento de outras (RAMSTAD, 2005 apud LEWIS; HECKMAN, 2006).

Alinhado à ideia de Lewis e Heckman (2006), no que diz respeito a prioridades de investimento e desenvolvimento, o gestor de pessoas da Empresa B destaca a importância da diferenciação entre Gestão de Talentos e Gestão de Pessoas, no que tange o direcionamento de recursos e oportunidades para os indivíduos que atingem desempenho acima da média. “Então gerir talentos eu acredito que seja realmente pegar os talentos que já são claros, e que a gente sabe que vai dar um resultado e ajudar eles no crescimento e botar eles nesses programas de desenvolvimento." Nesse sentido, a Gestão de Pessoas proporcionaria REAd | Porto Alegre - Edição 80 - N 1 - janeiro/abril 2015 - p. 222-247 
programas visando melhorar o desempenho daqueles que estão abaixo da média desejada, a fim de manter o diferencial competitivo da organização. O discurso dos outros dois gestores fica próximo do que Lewis e Heckman (2006), ao dizerem ser nada estratégico, na medida em que alegam que todos na organização são talentos e "conceitualmente não deveria ter diferença. Eu acho que as pessoas são talentos, e os talentos são pessoas". Entendido dessa forma, eles veem a Gestão de Talentos como uma modernização do nome Gestão de Pessoas, tendo foco no desenvolvimento individualizado e almejando impulsionar da carreira de todos. Ao considerar a modernização do nome GP para GT, um deles admite haver investimento diferente em uma parcela menor da organização, caracterizada como prioritária e com necessidade de políticas de retenção mais proativas. Ele, no entanto, não atribui o termo Gestão de Talentos a esse tipo de prática, sustentando assim o discurso de não haver distinção entre GP e GT na empresa em questão, uma vez que nela todos são talentos.

Na Instituição, a percepção da Coordenadora de RH mostra que a diferença entre Gestão de Pessoas e Gestão de Talentos foge dos critérios por ela destacados na diferenciação dos talentos. "A Gestão de Pessoas pra mim é seguir a normativa da nossa lei maior", enquanto a Gestão de Talentos é a capacidade de a Instituição criar mecanismos de motivação para uma geração nova que está entrando, a qual ela relaciona com a Geração Y. Enquanto, na definição da Gestão de Talentos, o conceito vem atrelado ao ingresso de uma nova geração, mais exigente de desafios, a definição pura de 'talento' foi vinculada ao desenvolvimento das capacidades técnicas do servidor. No entanto, retomando a perspectiva da Instituição, na qual a definição de talento é ligada também a conhecimentos, habilidades e atitudes, a correlação entre Gestão de Pessoas e Gestão de Talentos segue a mesma diretriz, aproximando-se da linha francesa de Gestão por Competências, que valoriza a mobilização do estoque de competências em prol de uma entrega que supere as expectativas (ZARIFIAN, 2001). Posto isso, validam-se os achados de Freitag et al. (2012) que constataram, nas abordagens sobre GT, atributos relativos à performance, ao potencial e à competência oriundos de uma literatura recente sobre potencial e competência aliada à entrega.

Embora tenham conseguido explicar a definição de talento, os gestores da Instituição tiveram dificuldades em detalhar o que seria a Gestão de Talentos propriamente dita, ficando apenas em um plano superficial, ao exporem que "a Gestão de Talentos é espécie do gênero Gestão de Pessoas" (Diretor de Controle e Fiscalização da Instituição). A GT parece, portanto, assemelhar-se muito mais à Gestão por Competências do que a um conjunto de ações de desenvolvimento específicas para determinado público, conforme destacado nas demais organizações pesquisadas.

REAd | Porto Alegre - Edição 80 - N 1 - janeiro/abril 2015 - p. 222-247 
O que as organizações entendem por gestão de talentos?

\subsection{Enfim, por que gestão de talentos?}

Levando em consideração a afirmação e a sustentação do discurso das organizações pesquisadas sobre a adoção da Gestão de Talentos em suas políticas e práticas, discutiu-se, como último ponto, a finalidade que as levou a implantarem esse estilo de gestão. As razões destacadas são diversas e convergem principalmente na atuação de que cada uma na sociedade.

A Empresa A atua no ramo da comunicação e por isso fica muito exposta, conforme a visão de um dos respondentes. Ele justifica sua opinião, afirmando que os profissionais desta organização estão constantemente em contato com diversos agentes do mundo corporativo, ficando sempre 'na vitrine'. Este entrevistado sente a necessidade de focar cada vez mais na captação de talentos para garantir a vantagem competitiva e a liderança. Ao mesmo tempo, percebe o quanto encontrar talentos vai se tornando mais complexo, devido às várias oportunidades disponíveis para quem assim é reconhecido no mercado de trabalho.

É raro hoje em dia tu encontrar uma empresa que não oferece pouca coisa em termos de remuneração, recompensa e de oferta de desenvolvimento para os seus melhores talentos, então tem uma baita guerra por talento, então eu acho que se a gente não tiver um processo de Gestão de Talentos muito robusto a gente fica absurdamente exposto. (Diretor Comercial da Empresa A)

Outro aspecto característico da iniciativa privada é a busca pelo lucro cada vez maior com a utilização cada vez menor de recursos, a famosa fórmula de tentar fazer mais com menos. O Gerente de Marketing da Empresa A destaca que um dos objetivos da implementação da Gestão de Talentos "passa basicamente por excelência operacional, por inovação, por produtividade, ganhar mais dinheiro gastando menos.”. Enquanto a visão dos gestores centra-se essencialmente na ideia de ganho de produtividade e inovação, no saber fazer de uma maneira cada vez melhor (otimizando recursos), a visão do RH abrange também a necessidade de formar sucessores capazes de ocupar posições determinantes dentro da organização.

Alinhada agora à segunda vertente identificada por Lewis e Heckman (2006), que vincula a GT ao planejamento sucessório, a Gestora de RH da Empresa A reconhece que a organização "tem muitos líderes com uma faixa etária e com um nível de experiência e conhecimento de negócio que a gente precisa preparar outras pessoas pra assumirem essas posições no futuro". O principal objetivo da empresa em gerir de maneira diferenciada os REAd | Porto Alegre - Edição 80 - N 1 - janeiro/abril 2015 - p. 222-247 
Dayane Scopel Ferrazza, Cecília Gerhardt Burtet \& Angela Beatriz Busato Scheffer

talentos é garantir profissionais capacitados "pra atingir o crescimento que a gente precisa nos próximos anos" (Gerente Executivo de Tecnologia da Empresa A).

De maneira ainda relacionada ao investimento e à disponibilidade superior que a Gestão de Talentos demanda tanto da organização quanto de seus gestores, o líder de pessoas da Empresa B destaca, como principal fator de adoção de uma Gestão de Talentos, “o fato de que os recursos são limitados. Eu acho que a restrição é tanto financeira, quanto de disponibilidade de tempo". Preponderantemente há, na Empresa B, a convicção de que todos na organização são talentos. O Gerente Geral da região Nordeste diz que "ter as melhores pessoas é central para o nosso sucesso, temos o processo de seleção mais difícil do mundo e investimos muito nisso". Fica evidente, nesta fala, o desejo de poder capacitar e desenvolver todos os colaboradores da organização de forma igualitária, no entanto a denominação de um público constituído pelos "talentos que mais se destacam" auxilia a distribuição dos investimentos associados a programas de desenvolvimento existentes. Lewis e Heckman (2006) consideram isto realmente estratégico.

Afastando-se de um cenário onde a restrição de recursos é um dos fatores que leva as empresas privadas estudadas a diferenciar esse público, para que o mesmo seja prioritário na designação de investimentos, a Instituição justifica a adoção de um modelo diferente devido à necessidade de atender as demandas da sociedade de forma cada vez mais competente e alocar internamente os servidores de modo correto. Tanto a Coordenadora de RH quanto o Diretor de Fiscalização relembram, nesse ponto, que, em função do concurso público, a Instituição não tem a possibilidade de selecionar perfis comportamentais para determinadas áreas e/ou funções. O principal objetivo de sua Gestão de Talentos é, pois, identificar o potencial e as capacidades dos indivíduos que se destacam em seu trabalho e alocá-los corretamente, seguindo o tradicional princípio de tentar "colocar as pessoas certas nos lugares certos" e "chamar pra essas auditorias especiais, pra comissões, pra trabalhos diferenciados, os diferentes" (Coordenadora de RH da Instituição).

A preocupação da gestão da Instituição em posicionar corretamente os profissionais por eles vistos como talentos advém principalmente do dinamismo que a Geração Y aporta consigo. Se a Instituição não proporcionar projetos desafiadores a seus servidores, esse público mais jovem não hesitará em buscar outras oportunidades, dentro da própria área pública, que lhe pareçam mais satisfatórias e estimulantes. O relatório da SHRM, publicado em maio de 2013, no qual a GT é indicada como prioridade principal entre os líderes de RH, mostra que o ingresso de muitos trabalhadores pertencentes à Geração Y e o esvaziamento de Baby Boomers do mercado de trabalho estão entre as principais tendências na perspectiva dos REAd | Porto Alegre - Edição 80 - N 1 - janeiro/abril 2015 - p. 222-247 
O que as organizações entendem por gestão de talentos?

profissionais de RH. Sarsur et al. (2003) inferem que, em uma época na qual riscos podem ser assumidos e a estabilidade já não se configura mais como um valor, é aconselhável focar estratégias que maximizem o desempenho do profissional durante sua permanência, com práticas aderentes à realidade.

Outro ponto destacado de maneira intensa pelos gestores da Instituição é a importância da qualificação da gestão pública para atender a sociedade com alto nível de qualidade. A preocupação em aproveitar os talentos (equiparados aqui com o conceito de competências) dos novos servidores é grande no sentido de usar essas habilidades e atitudes diferenciadas na entrega de algo a mais para a sociedade, algo que possa ajudar em sua transformação.

\footnotetext{
Há um conjunto de condições na sociedade que está chamando esse tipo de atuação diferenciada, qualificada. E dentro da Instituição há pessoas que percebem esse chamado, essa demanda, essa atração, como uma oportunidade de legitimação institucional, então nesses dois movimentos nós vemos um espaço para que determinados talentos se qualifiquem. (Diretor da Escola de Gestão da Instituição)
}

Em geral, nota-se que tanto a busca por competitividade quanto a legitimação das organizações perante a sociedade são fatores que impulsionam a adoção de um modelo diferenciado de Gestão de Pessoas, denominado pelas organizações pesquisadas Gestão de Talentos. Identificar os talentos e investir diferentemente neles é valorizar os indivíduos que contribuem de forma estratégica, bem como criar mecanismos para que as organizações possam dispor do talento para crescer e atender com excelência seu público consumidor, seja ele composto por clientes nacionais e internacionais, por telespectadores, seja pela sociedade como um todo.

\section{CONSIDERAÇÕES FINAIS}

A presente pesquisa, realizada com gestores de três organizações do município de Porto Alegre/RS, teve como objetivo levantar percepções sobre a definição de Gestão de Talentos e fazer uma análise comparativa, visando contribuir com a literatura nacional e internacional a respeito do tema. Pelas entrevistas com 12 gestores, observou-se que há, entre eles, definições diversas sobre o que se constitui como 'talento'. Apesar de muitos levarem em consideração a importância do desempenho na definição de talento, os critérios de forma geral ainda não são claros.

A análise geral das entrevistas evidenciou que todos os participantes responderam de forma afirmativa a pergunta inicial, dizendo que as empresas trabalham com o conceito de 
Gestão de Talentos. No entanto, a Empresa A caracteriza a Gestão de Talentos como um processo novo e que ainda está sob idealização do RH, não sendo amplamente difundido e consolidado entre os gestores das demais áreas, os quais têm uma percepção pessoal do que é talento e de como geri-lo. Na Empresa B, o conceito de Gestão de Talentos é exposto como um valor a ela inerente e que faz parte de seu jeito de ser e de fazer, estando vinculado muito mais à cultura do que associado diretamente a uma estratégia pontual de gestão. Há, divergência, portanto, das outras organizações pesquisadas. Na Instituição, a GT está em fase embrionária, o que pode justificar a confusão de conceitos existentes e a falta de alinhamento da opinião dos gestores, somado ao fato de se tratar de uma instituição pública, cujas particularidades devem ser consideradas.

$\mathrm{Na}$ Empresa A, de maior porte em relação às demais, a Gestão de Talentos é explicitamente conceituada como o 'clube dos raros', apesar da confusão de critérios para tal enquadramento. Por essa razão, há grande esforço por parte do RH em buscar parâmetros claros, que possam orientar os gestores no direcionamento assertivo das oportunidades de desenvolvimento para este público específico. O que chamou a atenção aqui é o fato da intitulação de talento ser momentânea, há utilização de programas periódicos que auxiliam a identificação de quem está enquadrado como talento naquele momento, funcionando como um 'retrato' que pode mudar semestralmente. A certeza da existência de um público com desempenho e potencial diferenciado deve-se à ideia de que uma organização com mais de mil colaboradores não pode ser composta única e exclusivamente por talentos, uma vez que não há recursos e oportunidades para todos. A empresa espera, através da Gestão de Talentos, atingir excelência operacional, obter vantagem competitiva e descobrir profissionais capacitados a assumirem posições-chave.

Durante a realização desta pesquisa, a Empresa A encontrava-se em processo de estruturação da Gestão de Talentos. Em 2014, este programa já se encontra implantado e difundido entre os gestores, entendido principalmente como a evolução da Gestão de Desempenho que, além de avaliar as entregas dos profissionais, avalia também a capacidade de aprendizado e de assumir novas responsabilidades em curto espaço de tempo. A nova métrica oferece aos líderes de Recursos Humanos mais insumos para a tomada de decisão em relação aos investimentos em pessoas e também para a correta alocação dos indivíduos, de acordo com o objetivo de crescimento da organização.

A Empresa B, única a associar o conceito de talento à cultura organizacional, sustenta que seu quadro funcional é composto integralmente por talentos, sendo isso garantido pelo processo seletivo extremamente rigoroso por ela adotado. Ficou evidente a dificuldade em REAd | Porto Alegre - Edição 80 - Nº 1 - janeiro/abril 2015 - p. 222-247 
O que as organizações entendem por gestão de talentos?

aceitar a existência de um público que é priorizado em função da entrega de um trabalho diferenciado, o que torna o reconhecimento dessa minoria um tabu dentro da organização. Mesmo a maioria dos entrevistados admitindo que, ocultamente, as práticas de diferenciação existem, apenas um entrevistado reconheceu haver diferença entre GT e GP. Ele observou, no decorrer da entrevista, a existência de um olhar diferenciado para aqueles que performam acima da média, denominado por ele Gestão de Talentos. O discurso predominante é de que o ramo de atuação e a natureza do negócio exigem uma força de trabalho composta, na totalidade, por talentos.

Consoante, em parte, com a Empresa B, alguns gestores da Instituição também ponderam que seu quadro de servidores é composto inteiramente por talentos. Eles consideram talento o indivíduo detentor de amplo conhecimento técnico e que, por isso, recebeu aprovação no concurso público, extremamente disputado. Outros respondentes vinculam a intitulação talento ao desempenho de cada servidor. Entendido assim, talentos seriam os servidores que entregam algo a mais e superam expectativas. A distinção entre GP e GT parece não estar clara entre todos. De forma geral, é vinculada à percepção de que a GP restringe-se ao cumprimento das obrigações legais e a GT gere aspectos comportamentais do indivíduo, assemelhando-se muito à abordagem de Gestão por Competências. O anseio pela implantação de uma GT na Instituição é justificado tanto pela necessidade de qualificação do corpo gerencial para melhor atender as exigências da sociedade, como pela emergência de ajustes na atual GP que proporcione o devido acolhimento da Geração Y.

Ficou perceptível que o uso da denominação GT está intensamente relacionado a uma estratégia específica na Empresa A; ao ramo de atuação na Empresa B; ao momento atual vivido pela Instituição. Em síntese, é notória a confusão de conceitos ainda existente sobre o tema Gestão de Talentos, advinda do uso de conceitos variados, com cada participante apropriando-se de um deles. Isso pode ter relação com a lacuna existente nos estudos publicados no Brasil e no exterior, os quais não sustentam uma teoria consolidada, abrindo espaço para a adoção de diferentes critérios na definição de Gestão de Talentos em âmbito organizacional. Ainda devido à falta de uma literatura consolidada, a GT carece de políticas e práticas consistentes para um público ainda incerto e indefinido, o que pode causar a apropriação indevida do conceito de Gestão por Competências, por ele se encontrar mais sólido e legitimado no universo corporativo.

Reforçam-se, pois, os caminhos para estudos futuros que ofereçam avanços na consolidação do conceito de Gestão de Talentos. Pretende-se dar continuidade à investigação

REAd | Porto Alegre - Edição 80 - Nº 1 - janeiro/abril 2015 - p. 222-247 
Dayane Scopel Ferrazza, Cecília Gerhardt Burtet \& Angela Beatriz Busato Scheffer

do tema na Empresa A, objetivando um estudo longitudinal, visto que esta organização planejava iniciar, pela primeira vez, seu programa de identificação de talentos, no mês de setembro de 2013.

Salienta-se que a revisão da evolução do conceito de gestão de talentos foi feita na área de administração, mas entende-se que o uso cotidiano do termo (presente tanto em passagens bíblicas com nas áreas da educação, do esporte, etc.) nas empresas colabora para a confusão conceitual existente e ressaltada nesse artigo. $\mathrm{O}$ entendimento da proposta de Ryle sobre a linguagem cotidiana dos termos também auxiliou este estudo, entretanto mereceria maior aprofundamento, em especial quanto às questões culturais. Muito da compreensão sobre a gestão de talentos advém da literatura norte-americana, podendo haver diferenças em relação ao uso cotidiano adotado no Brasil e, mais especificamente, no sul do país. Fica, pois, a proposta de continuidade ao estudo aqui desenvolvido.

\section{REFERÊNCIAS}

ALMEIDA, Walnice. Captação e seleção de talentos: Repensando a teoria e a prática. São Paulo: Atlas, 2004.

ASHTON, Chris; MORTON, Lynne. Managing talent for competitive advantage. Strategic Human Resource Review, 4(5), p. 28-31, 2005.

BARDIN, Laurence. Análise de conteúdo. Lisboa: Ed. 70, 2009.

BARRETO, Leilianne Michelle Trindade da Silva; SILVA, Maira Patricia da; FISCHER, André Luiz; DUTRA, Joel Souza; VELOSO, Elza Fátima Rosa; AMORIM, Wilson Aparecido Costa de. Gestão de Pessoas: Projetando Desafios e Tendências para 2015. In: Encontro da Divisão de Estudos Organizacionais da ANPAD, 6, 2010, Florianópolis. Anais... Florianópolis: EnEO.

BAUER, Martin W.; GASKELL, George. Pesquisa qualitativa com texto, imagem e som: um manual. Rio de Janeiro: Vozes, 2012.

BEECHLER, Schon; WOODWARD, Ian C. The Global Talent War. 2009.

COLLINGS, David G.; MELLAHI, Kamel. Strategic talent management: A review and research agenda. Human Resource Management Review, v. 19, n.4, p. 304 - 313, 2009. 
O que as organizações entendem por gestão de talentos?

DUTRA, Joel Souza. Competências: Conceitos e instrumentos para a Gestão de Pessoas na empresa moderna. São Paulo: Atlas, 2004.

FLICK, Uwe. Introdução à pesquisa qualitativa. 3. ed. Porto Alegre: Artmed: Bookman, 2009.

FREITAG, Bárbara Beatriz; FISCHER, André Luiz; ALBUQUERQUE, Lindolfo Galvão de; AMORIM, W. A. C. de; ALMEIDA, K. N. T. de. Gestão de Pessoas nos Anos 2000 em Organizações Brasileiras: Previsão de Tendências e Percepção de Incorporação. In: International Meeting of Iberoamerican Academy of Management (IAM), 7, 2011, Lima Peru. Anais... Lima: IAM Peru.

FREITAG, Bárbara Beatriz; OHTSUKI, Celi Hiromi; FERREIRA, Marcos Aurélio de Araújo. A Gestão de Talentos no campo da Gestão de Pessoas: tema emergente? In: Encontro Nacional da ANPAD - EnANPAD. Anais..., 2012. Rio de Janeiro - RJ: XXXVI EnANPAD.

GIL, Antônio Carlos. Como elaborar projetos de pesquisa. São Paulo: Atlas, 2009.

GODOY, Arilda Schmidt. Introdução à pesquisa qualitativa e suas possibilidades. Revista de Administração de Empresas. São Paulo, v. 35, n. 2, p. 57-63, 1995.

GOIS, Pedro Henrique de; BOLZAN, Larissa Medianeira; DEUS, Estéfani Sandmann de; SCHEFFER, Angela Beatriz Busato. Afinal, 'Quem São os Talentos da Organização?' Uma Análise do Discurso Sobre a 'Gestão de Talentos' na Literatura Acadêmica e na Mídia de Negócios de Gestão de Pessoas. In: Encontro Nacional da ANPAD - EnANPAD. Anais... , 2014. Rio de Janeiro - RJ: XXXVIII EnANPAD.

LE BOTERF, Guy. Desenvolvendo a competência dos profissionais. 3. ed. rev. e ampl. Porto Alegre: Bookman: Artmed, 2003.

LEGGE, Katherine. Human Resource Management: Rethorics and Realities. New York: Palgrave Macmillan, 2005.

LEWIS, Robert E.; HECKMAN, Robert J. Talent Management: A critical review. Human Resource Management Review, v. 16, p. 139 - 154, 2006.

MCCLELLAND, David C. Testing for competence rather than intelligence. American Psychologist, p. 1-14, 1973. 
Dayane Scopel Ferrazza, Cecília Gerhardt Burtet \& Angela Beatriz Busato Scheffer

MICHAELS, Ed; HANDFIELD-JONES, Helen; AXELROD, Beth.The War for Talent. Boston: Harvard Business School Press: 2001.

OLIVEIRA-CASTRO, Jorge M. "Fazer na cabeça": Análise conceitual, demonstrações empíricas e considerações teóricas. Psicologia USP, 4, 171-202, 1993.

OLIVEIRA-CASTRO, Jorge M.; OLIVEIRA-CASTRO, Karina M. A função adverbial de "inteligência": definições e usos em psicologia. Psicologia: teoria e pesquisa, v. 17, n. 3, p. 257-264, 2001.

ROSS, Suzanne. How definitions of talent suppress talent management. Industrial and Commercial Trainning, v. 45, n. 3, p. 166-170, 2013.

RYLE, Gilbert. Ordinary language. The Philosophical Review, 62, 167-186, 1953.

SARSUR, Amyra Myzes; PEDROSA, Rosangela Rezende; SANT'ANNA, Anderson de Souza. Onde estão os talentos? Onde está a Gestão de Recursos Humanos? In: Encontro da Associação Nacional de Pós-Graduação e Pesquisa em Administração. Anais... São Paulo: Anpad, 2003.

SHRM (Society for Human Resource Management). Wokplace Forecast: the top workplace trends according to HR professionals, May. 2013.

ZARIFIAN, Philippe. Objetivo competência: por uma nova lógica. São Paulo: Atlas, 2001. 